\title{
ANÁLISE DA PRODUÇÃO E UTILIZAÇÃO DO CAMARÃO NA GASTRONOMIA NATALENSE SOB PREMISSAS DO SLOW FOOD E DA ÉTICA SUSTENTÁVEL
}

\author{
ANALYSIS OF THE USE AND PRODUCTION OF SHRIMP IN NATAL'S \\ GASTRONOMY UNDER THE SLOW FOOD AND SUSTAINABLE ETHICS
}

\author{
Pedro Moisés Ribeiro de Paiva ${ }^{a}$ \\ Camila Kayssa Targino Dutra ${ }^{b}$ \\ Sueli Aparecida Moreira ${ }^{\mathrm{C}}$
}

\begin{abstract}
${ }^{a}$ Graduando em Turismo pela Universidade Federal do Rio Grande do Norte - DETUR

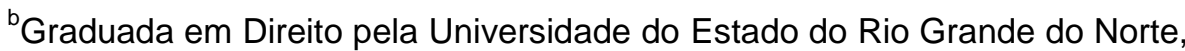
especialista em Ciências Penais pela Universidade Anhanguera-Uniderp; Discente do Programa de Pós-Graduação em Desenvolvimento e Meio Ambiente - PRODEMA pela Universidade Federal do Rio Grande do Norte - UFRN.
\end{abstract}

'Universidade Federal do Rio Grande do Norte - Departamento de Turismo - DETUR; Nutricionista (1996). Mestre em Saúde Pública pela Faculdade de Saúde Pública FSP/USP (2003). Atuou como Pesquisadora participante de 2005 a 2008 em projetos relacionados à populações vulneráveis em contexto do HIV/AIDS em São Paulo junto à FSP/USP. Desde 2005 vem estudando práticas alimentares populações vulneráveis em contextos urbanos. Em 2007 obteve o Premio Santander pra Estágio em Antropologia da Alimentação na Universidad de Barcelona. Obteve o título de Doutora em Ecologia (Ambiente e Sociedade) pelo Programa Interunidades entre 0 Centro de Energia Nuclear na Agricultura (CENA) e a Escola Superior de Agricultura Luiz de Queiroz (ESALQ) da Universidade de São Paulo/USP (2014). É docente da Universidade Federal do Rio Grande do Norte, UFRN desde 2009, para atuar em Nutrição Social: Antropologia e História da Alimentação, Educação Nutricional e Extensão Rural. Desde 2009 vem atuando junto ao Curso de Graduação em Turismo, em disciplinas sobre Identidade Cultural (Cozinhas Regionais; Gastronomia e Turismo; Alimentos \& Bebidas), com ênfase na Gastronomia enquanto Atrativo Turístico e na Gestão da Hospitalidade em Segurança Alimentar. Tem orientado projetos sobre Turismo Sustentável; Estudo da Comunidade; práticas tradicionais e da produção associada ao Turismo. Coordena o grupo de Pesquisa HIDEAS - Hospitalidade, Segurança Alimentar e Identidade Cultural com linhas de pesquisa em Comunidades, Segurança Alimentar e Turismo Sustentável entre outros.

Recebido em: 25/03/2017 I Aceito em: 09/06/2017 


\begin{abstract}
RESUMO
O Turismo representa uma oportunidade de desenvolvimento regional e a gastronomia é uma das principais áreas de apoio ao Turismo. $O$ presente estudo teve como objetivocaracterizar a prática da carcinicultura na culinária de Natal-RN, desde a produção e utilizaçãonos restaurantes sob as premissas do SlowFood.Trata-se de um estudo qualitativo, cujos dados foram coletados por meio de observação participante no local da produção, bem como a realização de entrevistas comprodutores da comunidade de Tibau do Sul, gestores da rede de restaurante Camarões e estudantes docurso de aquicultura da UFRN, totalizando nove sujeitos depoentes. Os resultados evidenciaram que há conhecimento empírico a respeito do termo Sustentabilidade, principalmente entre Gestores ligados à rede de Restaurantes Camarões. Contudo, na prática a produção de camarão é considerada somente sob o aspecto econômico. Verificou-se que a gastronomia de Natal-RNa base de camarão é muito insipiente em relação às premissas do SlowFoode da ética da sustentabilidade em dimensões sociais e ambientais.
\end{abstract}

Palavras-chave: Camarão. Culinária Potiguar. Consumo Sustentável. Ecogastronomia. Turismo. Desenvolvimento.

\begin{abstract}
Tourism represents an opportunity for regional development and gastronomy is one of the main areas of tourism support. This study aimed to characterize the practice of shrimp farming in Natal-RN cuisine, from production and use in restaurants under the premises of Slow food. This is a qualitative study, whose data was collected through participant observation at the site of production, as well as the realization of interviews with Community producers of Tibau do Sul, managers of the Camarõesrestaurant network and students of the aquaculture course of UFRN, totaling nine respondents. The results showed that there is empirical knowledge regarding the term sustainability, mainly between managers from Camarõesrestaurant network. However, in practice shrimp production is considered only under the economic aspect. It was found that the shrimp basegastronomy of Natal-RN is very insufficient in relation to the assumptions of Slow Food and the ethics of sustainability in social and environmental dimensions.
\end{abstract}

Keywords: Shrimp farming. Potiguar culture.Sustainableconsumption. Ecogastronomy Tourism. Development.

\title{
1 INTRODUÇÃO
}

O Turismo contribui para impulsionar o desenvolvimento regionalmotivado pela gastronomiaà base de produtos da terra. Uma fração desse segmento depende da atividade deCarciniculturaque compreende 0 cultivo do camarão branco-do-Pacífico, Litopenaeusvannamei, representa $28 \%$ da produção total da 
aquicultura nacional, e o Rio Grande do Norte lidera a produção de camarão marinho, sendo que em 2004 foi responsável por 41\% da produção nacional (OSTRENSKI et al, 2007).

Para atender a demanda turística sustentável, os restaurantes estão se comprometendo no uso racional de matérias primas (patrimônio natural) e na preservação de elementos históricos (patrimônio cultural) de uma localidade. Nesse sentido, a gastronomia pode ser definida no Brasil como um fenômeno social e econômico moderno.

De acordo com a Organização Mundial de Turismo (OMT, 2011), nos últimos anos, o Brasil vem apresentando um bom índice de crescimento no segmento em relação à média mundial.O turista tende a consumir a alimentaçãolocal com a finalidade de provar e conhecer um pouco a cultura do lugar. Conforme contextualiza Petrini (2010), o prato nunca é apenas a forma em que ele é apresentado, tem todo um contexto histórico por trás dele.

A gastronomiafaz parte da história da evolução humana e como afirma Schlüter(2003), ela não só ajudou na mudança da humanidade, mas também sofreu algumas alterações. Vislumbra-se que, com 0 advento da tecnologia e a modernização exacerbada, a gastronomia está passando por segmentações e alterações no modo de preparo e consumo dos alimentos.

Um exemplo claro dessas mudanças é o surgimento do "FastFood" (comida rápida, em tradução literal), que tem como principal objetivo ajudar no modo como as pessoas comem os alimentos se a vida está rápida é necessário que a comidaseja de fácil preparo e consumo(WEINER, 2005).

Por outro lado, há um movimento que vem ganhando muitos adeptos, conhecido atualmente como o"SlowFood" (comida lenta, em tradução literal), que engloba uma filosofia de vida e surge na tentativa de manter as tradições de cada lugar, além de comer bem tem como finalidade também compartilhar a cultura local.

Pessoas que seguem esse modo de vida dão uma maior confiabilidade e aceitabilidade aos produtos que são produzidos de maneira ecologicamente corretos e orgânicos onde geralmente estão presentes em pequenas produções. Como afirma o fundador do movimento Carlo Petrini (2004),o Slowfoodé um movimento 
que trabalha pela diversidade cultural da alimentação, da biodiversidade, da semente e das raças. Na diversidade reside a grande força do mundo. Essa perspectiva sustentável que prioriza a melhoria de todos, onde todos saem ganhando e de forma justa,confronta-se com o modelo padronizado e automatizado do FastFood.

Assim, esse estudo teve por objetivo caracterizar a prática da carcinicultura na cidade de Natal-RN, a partir das premissas do SlowFood, além de identificar e caracterizar a prática da carciniculturapara a ecogastronomia e práticas sustentáveis na cidade de Natal-RN. Também ocupou-se em verificar como se dá a percepção de sustentabilidade em relação aos aspectos sociais e ambientais da atividade gastronômica com base na produção e consumo de camarão.

\section{MÉTODO}

Este estudo possui natureza qualitativa cujos dados foram obtidos por meio de observação participante e esta contou com o uso auxiliar de instrumento para coleta de dados. A pesquisa foi realizada junto à população ribeirinha do município de Tibau do Sul - RN, responsável pela criação de camarão, a Rede de Restaurantes Camarões, em que envolveu o gestor do referido e entrevistaram-se também estudantes do curso de Aquicultura da Universidade Federal do Rio Grande do Norte - UFRN a fim de mensurar como está fomentada a ideia de sustentabilidade em criações de camarão em Tibau do Sul.

Assim foram entrevistados 9 sujeitos envolvidos com a produção e utilização do camarão, sendo que 3 deles eram ribeirinhos produtores; 3 eram estudantes de aquicultura e 3 eram gestores da rede de Restaurantes Camarões.

Os dados foram obtidos por meio de observação participante e entrevistas semi-estruturadas mediante a utilização e assinatura do Termo de Consentimento Livre e Esclarecido conforme a Norma CNS 466/12. As entrevistas foram gravadas em mídia digital e após, foram transcritas para melhor análise e interpretação dos dados. 


\section{REFERENCIAL TEÓRICO}

\subsection{TURISMO E GASTRONOMIA SUSTENTÁVEL}

Associar patrimônio gastronômico e turismo é algo fundamental para o sucesso da atividade. Para Leite (2004, p. 02), a gastronomia "refere-se à arte de preparar as iguarias, tornando-as mais digestivas, de modo a obter o maior prazer possível".

Para Schlüter(2003),o significado de gastronomia é amplo e complexo, enquantoYurtseven (2001) afirma que a gastronomia compreende desde a noção básica de como é feita a alimentação, comose caracteriza o comensalismo, até o processo de obtenção de nutrientes e energia para manter o corpo saudável e de como tal prática influencia no nosso modo de agir, pensar e relacionar-se com os demais.

A gastronomia enquanto atrativo turístico também contribui para o desenvolvimento da localidade. Alimentar-se é uma necessidade básica, contudo o turismo gastronômico oferece a oportunidade de lazer em contraponto ao consumismo cotidiano. Nesse sentido, a Associação Brasileira de Gastronomia, Hospedagem e Turismo (ABRESI, 2015) ciente do papel vital da alimentação, promove a gastronomiacomo importantecomponente na oferta de um destino turístico. De acordo com dados da ABRESI (2015) o setor fatura em média 2,4\% do Produto Interno Bruto - PIB sendo também, responsável por 8\% dos empregos diretos, e gera emprego para mais de seis milhões de pessoas.

A gastronomia é um dos principais motivos para a criação e desenvolvimento dos diferentes destinos turísticos, sendo um patrimônio intangível (SCHLÜTER, 2003), nesse sentido, o presente estudo se propôsa caracterizar alguns aspectos como: a gastronomia local, apresentando suas raízes; constatar se há ou não uma segmentação na culinária que o nativo desfruta em relação ao que o turista procura e se tal fenômeno afeta na gastronomia local e na atividade turística.

As muitas maneiras de alimentar-se, bem como os produtos consumidos e a forma de cozinhá-los relacionam-se com os recursos locais, as características do clima, solos, território, as formas de produção, a agricultura, a pecuária e também o 
comércio. A alimentação relaciona-se ainda aos conhecimentos tradicionais, com as práticas culinárias inscritas em todo o contexto socioeconômico de determinado local. Nesse contexto, para Canesqui eDiez-Garcia (2005) esse conjunto de elementos e tudo que a ele se relaciona são percebidos como marcadores étnicos e até a identidade passa a ser a associada à cozinha nacional ou regional.

A emergência da cozinha étnica configura perfeitamente no contexto turístico sustentável. As pessoas identificam-se e também se expressam através da gastronomia. Segundo Yurtseven (2001, p. 17) "para o novo turista, em especial, todas as facetas da viajem são cruciais e a gastronomia oferece a oportunidade de vivenciar experiências de valor concreto, as quais serão internalizadas pelo viajante", reforçando a ideia de que a gastronomia é responsável por gerar confortoa maioria das atividades turísticas.

Cada sociedade é munida de tradições e costumes e o turismo usa desse elemento para assim atrair visitantes que são motivados manifestações culturais inseridas tanto no âmbito urbano como rural. A interiorização do turismo e apreciação da cultura sertaneja, das cozinhas e fazendas constituem alternativas para fortalecer o desenvolvimento regional, bem como divulgar comunidades tradicionais, pequenos produtores rurais e funciona como meio de gerar renda a partir da produção associada ao turismo.

O papel sócio vital desempenhado pela alimentação proporciona a gastronomia um forte aliado do Turismo. Para Schlüter (2003), ao mesmo tempo, que $o$ ato de se alimentar possibilita o crescimento de uma classe social, atua também como diferencial de uma cultura para com a outra, reconhecendo também que ao comer, incorporam-se além de características físicas, elementos simbólicos e imaginários.Um dos aspectos que torna a gastronomia um fator sustentável é que ela preserva o meio ambiente e mantem vivo o patrimônio cultural:

\footnotetext{
Alimentos assumem funções simbólicas e assumem um significado moral, tornam-se um meio para expressão estética, dando origem a elaboradas preparações e cozinhas que não podem ser justificadas apenas em termos de fatores nutricionais (ROZIN,2005, p.107).
}

Uma das vertentes da gastronomia sustentável envolve a presença de aspectos culturais, e está caracterizada uma série de atrativos autênticos, conforme 
afirmam Nilsson et. al. (2011), a mesma deve priorizar o patrimônio local, o ambiente e a economia social, os investimentos na gastronomia sustentável devem ser direcionados para as cozinhas com ingredientes predominantes e característicos da região.

A sustentabilidade da matéria prima da gastronomia é outro fator que detêm uma importância maior. Alguns alimentos são mais difíceis de serem produzidos ou encontrados, gerando até mesmo impactos ambientais, nesse sentido, de acordo com a Associação Brasileira de criadores de Camarão - ABCC(2015), a atividade da criação de camarãono Rio Grande do Norte, vem ganhando muito espaço nos últimos anos, tornando o estado um dos maiores produtores de camarão cultivado no país, tal proeza é justificada pela condição climática favorável e disponibilidade de áreas apropriadas para tal atividade.

De acordo com Queiroz (2008, p.2), manter "a gastronomia regional é assegurar a subsistência e manutenção da cultura de um povo". Logo, devem-se considerar os aspectos culturais que estão inseridos no prato que é servido, tendo também a preocupação de preservar o seu modo de preparo.

Em contextos regionais, a peculiaridade de um local pode aumentar o valor tanto dos custos como o interesse em se conhecer um local "exótico" e diferente do seu cotidiano (FAGLIARI, 2005). E para os elementos gastronômicos vale a mesma regra, quanto maior o seu diferencial mais interessante será a atração do turista. Para reforçar tal ideia,Krippendorf (2000)ressalta que no mercado internacional do turismo, em que todas as ofertas são formuladas da mesma maneira, uma singularidade assim se torna cada vez mais necessária.

De acordo com Azambuja(2000) algumas localidades se aproveitam de terem as suas raízes, tradições e expressões culturais presentes na culinária para fomentar e promover o seu atrativo turístico, ao deterem contextos favoráveis à aplicação da teoria de gastronomia sustentável.

\subsection{O MOVIMENTOSLOW FOOD}

Originalmente o SlowFood foi criado pelo italiano Carlo Petrini no ano de 1986 na Itália, e surgiu em decorrência da abertura de uma grande Multinacional que comercializava comidas prontas e de rápido consumo. Com uma filosofia que visa promover a cultura ecogastronômica e com um pensamento sustentável, logo, seu 
conceito foi crescendo gradativamente com adeptos em todo o mundo (WEINER, 2005).

Algumas matérias primas tradicionais compõem a produção artesanal de alimentos, diminuindo a globalização e a industrialização da dieta, pois a massificação oferecida peloFastFood, contribui para ahomogeneização de alguns alimentos, bem como o modo de consumo, ao ponto de uma completa extinção de diversos rituais que envolvem alguns aspectos culturais gastronômicos.

De acordo com Weiner (2005), oSlowFood acredita que o prazer de comer uma boa comida ajuda a preservar os inúmeros alimentos e tradições que estão desaparecendo em virtude do predomínio de refeições rápidas (WEINER, 2005). Segundo o autor, a filosofia do SlowFoodconsidera que comer bem é partilhar uma refeição e manter as tradições de cada lugar, aproposta do movimento é mesclar o prazer de comer à mesa com consciência e responsabilidade, defendendo por meio de estudos a biodiversidade na cadeia alimentar e a aproximação entre produtores de pequeno porte e os consumidores.

Tal segmento fundamenta um alimento SlowFood em três pilares: bom, limpo e justo. Bom: porque o alimento tem que vir de um processo de produção de qualidade; Limpo: devido à ausência de agrotóxicos e Justo: porque todos que compõe esse processo recebem o devido valor empregado, o SlowFood conjuga o prazer e a alimentação com a consciência e responsabilidade(WEINER, 2005).

Ainda inserido nesse contexto, o tópico a seguir aborda questões relacionadas a atividade de Carcinicultura no estado do Rio Grande do Norte.

\subsection{A CARCINICULTURA NO PAÍS E ALGUNS ASPECTOS NO RIO GRANDE DO NORTE}

De acordo com Rocha (2010), a história da produção de camarão marinho cultivado (carcinicultura) teve início no Brasil em 1970, a partir da adoção de modelos importados do Equador, do Panamá e dos Estados Unidos. Após décadas de intenso aprimoramento alcançou-se uma tecnologia apropriada e adequada à realidade nacional, o que contribuiu para colocar o país na condição de líder mundial em produtividade de camarão em 2003. 
Segundo a Associação Brasileira de Criadores de Camarão - ABCC (2015), o Brasil está inserido em um panorama de crescimento da Aquicultura. Conforme dados da ABCC (2015), comercialmente o camarão marinho cultivado é o principal segmento da aquicultura brasileira cuja produção, em 2002, foi de 60.128 toneladas e sua maior parte para exportação.

Em 2004, a produção de camarão marinho atingiu 75.904 toneladas, enquanto a carcinicultura de água doce com a espécie Macrobrachiumrosenbergii representou no ano de 2004 apenas $0,1 \%$ (363 toneladas) da produção total da aquicultura brasileira. A região Nordeste contribuiu com $16 \%$ da produção de camarão de água doce (OSTRENSKYet al., 2007, p.67).

Estudos do Departamento de Economia da Universidade Federal de Pernambuco/UFPEapontam duas características que marcam o crescimento do cultivo do camarão no Brasil: a geração de empregos de forma indireta e direta e a participação do pequeno produtor. Tal fato contribui para que o camarão se torne o produto mais importante do setor agropecuário da Região Nordeste e representa ainda, o segmento mais dinâmico na geração de economia no setor primário brasileiro.

Segundo a ABCC (2015) o Brasil hoje é o oitavo produtor mundial de camarão em cativeiro. Tal proeza provém da capacidade de adaptação, manejo e criação do camarão marinho da espécie Litopenaeusvannamei conhecido como camarão branco, um dos mais cultivados no país e na região Nordeste.

O Estado do Rio Grande do Norte está incluído como sendo um dos maiores produtores de camarão cultivado no país, chegando a produzir quase 7 toneladas de camarão por ano, (ABCC, 2015). Tal posicionamento está ligado a fatores climáticos e a grande disponibilidade de áreas tropicais para a exportação da atividade.

Todavia, há questões que são importantes e devem ser mencionadas, nesse sentido, conforme Oliveira(2007), a rápida expansão desse setor tem gerado grande concentração de fazendas de produção e a questão da distribuição geográfica das unidades de cultivo implantadas e em implantação, somada à intensificação dos cultivos, tem levado o setor a preocupar-se com a capacidade de suporte dos tanques, no que diz respeito à qualidade da água e a assistência técnica para os pequenos produtores. 
Outro questão apontada pela ABCC (2015) é a dificuldade encontrada pelos produtores em regularizar a criação de camarão junto aos órgãos responsáveis pelo licenciamento da respectiva atividade. Pois é notória a grande discrepância nos dados oficiais sobre o número de fazendas que estão em situação de regularidade, em relação ao que é produzido e em quais condições a produção a realizada.

Com o fim de avaliar e discutir os dados obtidos o tópico a seguir é dedicado a expor os resultados e a promover a discussão da pesquisa empreendida.

\section{RESULTADOS E DISCUSSÃO}

\subsection{PERFIL SOCIODEMOGRÁFICO DOS ENTREVISTADOS}

A partir da pesquisa realizada, é possível realizar o perfil sociodemográfico dos entrevistados. Nesse sentido, constatou-se que os três produtores de camarão são do sexo masculino e na faixa etária de 38 a 40 anos. Dois deles haviam cursado o ensino médio, mas apenas um está cursando o ensino superior. Observou-se também a ausência de mulheres na produção de camarão, ao ser questionado a respeito disso, o Produtor 01 entrevistado, assim respondeu:

\footnotetext{
É uma atividade muito grosseira, precisa de força. Não que a mulher não tenha força para trabalhar e pegar no pesado, mas, é muito exaustivo você precisa ficar no sol por muito tempo, tem que pegar em coisas que mulheres têm nojo. E, não se tem a presença de mulheres na produção mas na área de administração elas estão presentes, minha mulher é uma que me ajuda muito nessa parte (Entrevista-Produtor 01).
}

Constatou-se também que aexecução da produção de camarão é de domínio masculino e resumem-se as tarefas operacionais rotineiras e pouco criativas, contudo a presença do sexo feminino é notada na administração e logística da produção de camarão,onde as mulheres auxiliam na finalização do ciclo de produção.

Em relação aos gestores da rede de restaurantes Camarões, foram entrevistadas três pessoas, sendo duas mulheres e um homem. As mulheres tinham entre 25 e 28 anos. Quanto aos estudantes docurso de Aquicultura da UFRN, foram entrevistadas três pessoas, incluindo duas mulheres e um homem, as idades variavam entre 40 anos (homem) e 28 a 30 anos (mulheres), conforme o perfil sociodemográfico abaixo: 
Figura 01: Perfil sociodemográfico de participantes da pesquisa realizada, RN 2016.
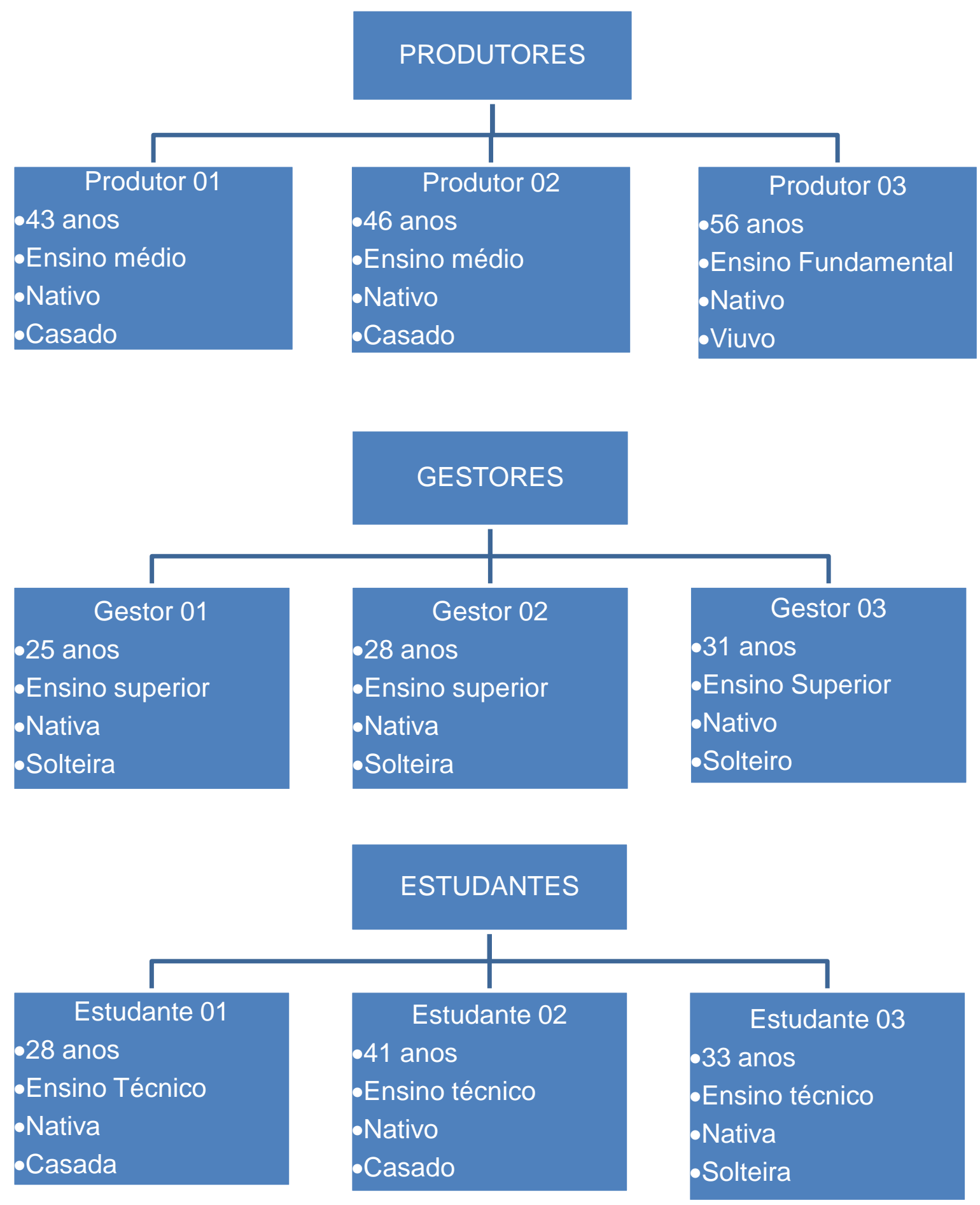

Fonte: Dados da pesquisa (2016).

Como importante aspecto inserido na pesquisa empreendida, a Ciência e Sustentabilidade - CeS / Juazeiro do Norte, v. 3, n. 1, p. 142-165, jan/jun 2017 
Sustentabilidade foi avaliada na percepção dos entrevistados. E nesse contexto, o tópico a seguir expõe esse assunto com mais detalhes.

\subsection{SUSTENTABILIDADE E A PERCEPÇÃO DOS ENTREVISTADOS}

Constatou-se que a percepção de Sustentabilidade que os produtores possuem, não está embasada em um conhecimento mais formal, isto é, mais acadêmico e/ou científico. Mas, este fato não inviabilizou os produtores de possuírem certo posicionamento a respeito desse assunto. Em verdade, os produtores têm uma percepção convicta a respeito da Sustentabilidade a partir do conhecimento empírico que os mesmos detêm.

E assim, a Sustentabilidade foi um termo bem presente na fala de todos os produtores de camarão. Eles foram incisivos e se disseram comprometidos em todas as etapas dos respectivos processos de trabalho, conforme verifica-se no relato a seguir: "Sustentabilidade é o que podemos fazer para que o que temos hoje seja durável para as gerações futuras. São coisas que temos que fazer em conjunto com órgãos públicos e privados" (Entrevistado Produtor 01).

Nos depoimentos, notou-se a presença de consultoria técnica nas ações que são desenvolvidas e noprocesso de criação de camarão. Parece haver uma ação conjunta com outro órgão, mas não foi possível identificar a natureza da ação e ou da empresa. Também não foi possível identificar se há critérios técnicos subsidiando esses processos de produção ou se é algo que foi sendo instituído naturalmente até que o produto final apresente aspecto de boa qualidade. No relato a seguir, verificase o que o entrevistado compreende a respeito da sustentabilidade:

Por sustentabilidade compreendo que será o uso consciente de agentes que podemos utilizá-los através do tempo e deixá-los para gerações futuras, de modo a respeitar e trabalhar junto com o meio ambiente, a sociedade $e$ políticas para que não possamos comprometer o futuro dos recursos e suprir as necessidades atuais(Entrevistado Produtor 01).

Por fim, o termo sustentabilidade entre os produtores, possuem alguns aspectos. Sendo eles: ambiente, pessoas e outros meios que possam facilitar a tal ação.

Por outro aspecto, informam os autores Costa e Scocuglia (2008, p. 86) "quea preocupação com a sustentabilidade está presente em todas as formas de produção 
e consumo, inclusive na produção do espaço". Os autores advertem que, no contexto urbano, onde implicam ações em várias escalasé preciso incorporar a sustentabilidade em seus conceitos, princípios e diretrizes ainda na fase de projeto.

Foi constatado que o conceito de sustentabilidade estáinserido na metodologia de produção de camarão dos produtores, conforme se depreende do relato a seguir:

\begin{abstract}
Sim. Temos ações em nossos criadouros que possibilitam agir de forma correta com nosso produto e com nossa cidade. Temos o processo padrão que a cada 15 dias fazemos coletas de água e do camarão para poder mensurar o quão poluído ou modificado a água e o ambiente ficou. Podemos vê quanto pesa e quanto mede o camarão através da biometria, analisamos a salinidade da água, temos a preocupação de vender um camarão padrão e correto do que é estipulado pelo IDEMA. Observamos também fatores de solo, água e aspectos sociais e por isso, julgo o nosso método de criação sustentável (Entrevistado Produtor 01).
\end{abstract}

Durante a observação participante do processo de produção foi possível verificar que é realizado todo esse aparato nas etapas de produção. Por outro lado, constatou-se junto à outra produção de camarão na mesma localidade, em Tibau do Sul, uma realidade bem diferente da anterior, conforme o relato a seguir:

No que se diz respeito a minha comunidade, sustentabilidade passa longe! Para alguns produtores a mesma está resumida apenas como um fator econômico. Acredito que as preocupações sejam apenas em apresentar ou vender um produto de boa qualidade. Enquanto que as preocupações ambientais e sociais estejam distantes do conceito sustentável (Entrevistado Produtor 02).

O IDEMA, em 2007, realizou algumas pesquisas em que mostrou um resultado final não muito satisfatório em que: "a quantidade de fazendas que operam de forma irregular, por falta de licenciamento e/ou também por avanço das construções dos tanques sobre áreas de preservação ambiental, é bem superior do que as fazendas licenciadas." Tal problema gerava um grande índice de desmatamento, chegando até em áreas de preservação ambiental.

Para solucionar tal problema, o IDEMA criou um Plano de Recuperação de Áreas de Preservação Permanente (PRAPP), que tem por objetivo informar e propor a recuperação das áreas de preservação ambiental degradadas por consequência da prática da carcinicultura local. Tal plano deve conter os procedimentos que serão executados nas demais fazendas de criação, tudo organizado em um cronograma.

Em acordo com a ideia de Benni (1999) de que o planejamento é o processo que abrange três pontos essenciais e distintos: estabelecimento de objetivos, Ciência e Sustentabilidade - Ces / Juazeiro do Norte, v. 3, n. 1, p. 142-165, jan/jun 2017 
definição de cursos de ação e determinação da realimentação, toda atividade produtiva interage de forma interdependente com seus componentes. E inserido no âmbito da gastronomia, equivale a conhecer a proveniência equais métodos para produção são utilizados. Nesse contexto, uma das questões realizadas englobouaveriguar como foi apreendido o método utilizado na criação de camarão, conforme o relato a seguir:

Seguimos o modelo padrão e que todos temos que seguir. Quem estipula como tem que ser feito a criação e todo o método utilizado na produção e criação do camarão é a licença ambiental concedida pelo IDEMA. Nisso seguimos a regra, nos adequamos a nossa realidade e aplicamos aqui" (Entrevistado Produtor 01).

E assim, a cada pergunta e resposta obtida tornava-se mais nítida a presença de um órgão ou entidade que rege tal produção. Sendo por meio desse órgão que os produtores têm o aval para produzir e comercializar o seu produto.

É sabido que oIDEMA tem como missão "promover a política ambiental do Rio Grande do Norte, visando o desenvolvimento sustentável, aproveitando as potencialidades regionais em busca da melhoria da qualidade de vida da população" (IDEMA, 2016), mas, que muitas vezes o pequeno produtor não consegue suprir essa necessidade de atender com boa qualidade uma ação sustentável perante a comunidade, pois, tendem a se adequar as normas exigidas pelo instituto a fim de legalizar sua produção deixando a desejar no que se diz, de fato, sustentabilidade social.

\subsection{APROVAÇÃO DO CAMARÃO COMO PRODUTO GASTRONÔMICO E A PRODUÇÃO DE CAMARÃO, RENDA E MEIO AMBIENTE}

Esse tópico tem por intuito compreender de como o camarão é visto na comunidade, isto é, se é um produto destinado apenas para relações comerciais ou se também, algo que a comunidade agrega algum valor. Nesse sentido, foiquestionado aos ribeirinhos se o camarão produzido em sua comunidade é também consumido pelos nativos, conforme o relato a seguir:

Sim. Sabemos como ele é criado e sabemos de sua procedência. Há questões de técnicas que influenciam no gosto e tamanho do camarão. Consumimos também porque é algo feito em nossa localidade, dar preferência a eles é de grande importância. "Além do quê, se for comprar 
camarão de outras localidades sairá bem mais caro" (Entrevistado-Produtor 03).

O discurso de consumo do camarão produzido na localidade de Tibau do Sul é bem presente em seus nativos, eles costumam consumir do seu produto, conforme verifica-se nos relatos do Entrevistado-Produtor (3):"É mais gostoso, não é industrial, congelado, sem cor ou gosto'"'Sabemos quem faz, fica mais fácil confiar para comer".

O discurso da comunidade produtoraretrata enfaticamente o camarão sob a ótica da produção. Nesse tópico temos como foco saber como está fomentado o processo de criação de camarão e se ele é benéfico à comunidade e ao meio ambiente. Na opinião do Entrevistado-Produtor (3), devido a atividade, relatou que: "Temos emprego para as pessoas que moram aqui". Outros depoimentos enfatizam que:

\begin{abstract}
No aspecto social, posso falar que é um grande gerador de emprego. No aspecto ambiental posso afirmar quê, onde se tem um criadouro de camarão hoje, futuramente esse solo será infértil caso querem mudar de produto. São usadas muitas substâncias para se ter um fácil crescimento e os camarões possam chegar a um bom peso, nisso a água com um tempo precisa ser trocada, esse processo de desintoxicação também leva alguns produtos que ajudam a limpar a água mas que agridem outras coisas, como o solo. É um ciclo vicioso e perigoso para o meio ambiente (EntrevistadaProdutora 01);

É bom, a gente vende, trabalha e come do nosso produto, o produto que é feito na nossa cidade. Ter pontos negativos todo mundo tem! O povo reclama que aqui fede, não acho. Já me acostumei (Entrevistado-Produtor 03).
\end{abstract}

Mediante três depoimentos de pessoas diferentes, em cada um percebe-se algo sobre a produção que é feita nessa comunidade. O primeiro enfatiza o método, sem deixar de lado o que esses processos podem causar ao meio ambiente. É levado em consideração tudo que é feito, inclusive os males que são causados por essa atividade, mas, mesmo assim, essa atividade segue movimentando a economia local.

A partir do segundo relato, tem-se um olhar mais puro e um pouco leigo sobre tudo o que acontece nessas produções. É levado em consideração apenas o que atividade trazem curto prazo. Por ultimo, tem-se a visão de um produtor ribeirinho, que demonstrou desinteresse em notar os problemas enfrentados na rotina de produção. Como por exemplo:Será que o mau cheiro, citado por terceiros, não quer dizer que algo nessa produção vai mal? Será que esse "já me acostumei" não é uma Ciência e Sustentabilidade - CeS / Juazeiro do Norte, v. 3, n. 1, p. 142-165, jan/jun 2017 
reação te todos na comunidade por saber que isso não pode ser mudado ou revisto para que seja feito de um outro modo, que não cause esse dano?Será que parte do problema pode ter sido a falta de coordenação entre a politica de desenvolvimento e ambiental conforme advertiu Benni, (1999). No Quadro 01, abaixo constam os principais problemas decorrentes da carcinicultura:

\section{QUADRO 01: Tipos de impactos ambientais decorrentes da carcinicultura.}

\begin{tabular}{|c|c|c|}
\hline Tipos de impactos & Causas & Efeito \\
\hline $\begin{array}{l}\text { Construção de barreiras, } \\
\text { taludes e tanques. }\end{array}$ & $\begin{array}{l}\text { Acúmulo de água no } \\
\text { sedimento; impedimento da } \\
\text { entrada das marés. }\end{array}$ & $\begin{array}{l}\text { Impedimento de trocas gasosas } \\
\text { e hipersalinidade; evaporação } \\
\text { da água do sedimento e } \\
\text { aumento da temperatura e da } \\
\text { salinidade. }\end{array}$ \\
\hline Construção de canais & $\begin{array}{l}\text { Canalização e desvios de } \\
\text { fluxos de água. }\end{array}$ & $\begin{array}{lcc}\text { Redução no } \quad \text { aporte } & \text { de } \\
\text { nutrientes; } & \text { acúmulo } & \text { de } \\
\text { substâncias } & \text { tóxicas } & \text { no } \\
\text { sedimento. } & & \end{array}$ \\
\hline $\begin{array}{l}\text { Sedimentação por erosão } \\
\text { do } \\
\text { talude e descarga de } \\
\text { efluente. }\end{array}$ & $\begin{array}{l}\text { Sufocamento das raízes } \\
\text { respiratórias. }\end{array}$ & $\begin{array}{l}\text { Impedimento das trocas } \\
\text { gasosas. }\end{array}$ \\
\hline $\begin{array}{l}\text { Contaminação por } \\
\text { patógenos, hormônios, } \\
\text { carrapaticidas, compostos } \\
\text { químicos, resíduos } \\
\text { alimentares e fertilizantes } \\
\text { lançados por afluentes } \\
\text { dos tanques. }\end{array}$ & $\begin{array}{l}\text { Aumento do aporte de } \\
\text { nutrientes: Acúmulo de matéria } \\
\text { orgânica no sedimento; } \\
\text { Contaminação de peixes e } \\
\text { mariscos por agentes } \\
\text { patogênicos; Perda de } \\
\text { qualidade das águas } \\
\text { estuarinas; contaminação por } \\
\text { substâncias químicas. }\end{array}$ & $\begin{array}{l}\text { Efeito positivo - incremento no } \\
\text { crescimento do mangue, e feito } \\
\text { negativo - excesso causa a } \\
\text { mortalidade das espécies } \\
\text { vegetais e eutrofização da } \\
\text { coluna da água; } \\
\text { Efeitos danosos na fauna e } \\
\text { flora botânica; Mortandade das } \\
\text { espécies da importância } \\
\text { econômica; queda da cadeia } \\
\text { trófica; Morte das espécies da } \\
\text { fauna e flor dos estuários, } \\
\text { manguezais e ecossistemas } \\
\text { adjacentes. }\end{array}$ \\
\hline $\begin{array}{l}\text { Introdução de espécies } \\
\text { exóticas. }\end{array}$ & $\begin{array}{l}\text { Competição, destruição } \\
\text { habitat, predação. }\end{array}$ & $\begin{array}{l}\text { Ainda há poucos indícios e } \\
\text { estudos que relatam tais } \\
\text { alterações. }\end{array}$ \\
\hline
\end{tabular}

Fonte: Santos,M. et al. (2005). 


\subsection{PREÇO JUSTO E SLOW FOOD}

Outro fator que deve ser observado é o preço pago pelo camarão e pela mão de obra envolvida no processo de criação do mesmo, tendo em vista que para o movimento SlowFoodespera-se umalimento limpo, sustentável e justo (PETRINI, 2009).

E assim, sob essas premissas, buscou-se investigar se o preço pago pelo produto final e pela mão de obra é também justo e satisfatóriopara a comunidade e produtores, e de acordo com o Entrevistado-Produtor (01): "Sim. O preço depende, também, da demanda. Mas o preço pago pelo camarão produzido aqui é bastante justo. Até porque conseguimos sobreviver só dessa criação de camarão". A partir do relato exposto, pode-se afirmar que o Produtor (01) entende que é justo o valor pago pelo camarão, levando em consideração também a sazonalidade da demanda.

Por outro lado, verificou-se um relato diferente no local em que é realizado as práticas de criação do camarão:"As vezes não. Tem empresas que por verem que não somos uma criação de grande porte, acham não podemos apresentar um produto final de boa qualidade. Isso as vezes gera um mal estar na hora de fechar negocio" (Entrevistado-Estudante 02).

Nesse aspecto, percebe-se certa resistência em pagar um preço justo ou o preço do mercado para criadouros de pequeno porte. Isso é um ponto bastante delicado de se tratar, pois, as multinacionais ou empresas de que dependem desse camarão, querem um produto de grande qualidade e, atrelado a isso, têm uma visão (errônea) de que só os grandes criadouros ou grandes produtores é que tem a capacidade de te devolver um produto de boa qualidade. O que gera um pensamento equivocado.

Muitas vezes, nas pequenas produções a atenção é direcionada à qualidade do produto final e em todas as etapas de criação do mesmo para que assim possam entregar um produto de boa qualidade. O que pode não ocorrer em empresas que industrializam tudo e passam por algumas etapas de produção. Em síntese, o preço pago pelo camarão na visão de seus produtores da comunidade ribeirinha é bastante satisfatório isso pode se confirmar com essa fala:"Acho, justo até demais. 
Imagina se não fosse justo, a gente já teria fechado nossas portas" (EntrevistadoProdutor 1).

Nesse estudo também se verificou a percepção dos Gestores da rede de Restaurantes Camarões, buscando analisar como está fomentada e organizada a ideia de um ciclo sustentável, bem como se esse ciclo engloba apenas a produção ou se envolve todos os atores como um todo, desde a produção, passando pelos produtores até chegar ao consumidor final.

Nesse contexto, um dos questionamentos realizados teve como intuito constatar se os Gestores sabiam como se dá o processo de criação do camarão, tendo em vista também, este ser o principal ingrediente de vários pratos da culinária do município de Natal, e nesse sentido, assim foi relatado pelo Entrevistado-Gestor 03: "temos uma longa parceria com a empresa Tecnarão, de quem compramos a maior parte do nosso camarão, mas adquirimos de outros também como alguns de Tibau do Sul, todos eles no Rio Grande do Norte".

Uma das primeiras constatações foi que a rede de Restaurantes Camarões com o seu nome reconhecido em todo o território nacional, adquire matéria-prima (o camarão) de produtores da comunidade de Tibau do Sul. E assim, buscou-se verificar também, se havia por parte do Restaurante Camarões alguma ação realizada ou projeto que tenha o intuito de trazer benefícios às comunidades que produzem camarão, isto é, se há alguma ação social, o que foi respondido pelo Entrevistado-Gestor (3): "O Camarões só compra o produto de empresas licenciadas pelos órgãos ambientais, o que nos faz pressupor que elas mantêm práticas condizentes com a sustentabilidade da atividade".

A partir disso, observou-se que a empresa não utiliza de nenhum outro artifício para ajudar a comunidade. Levando em consideração apenas o fator de que a empresa só pode comprar produtos de produtores ou criadores de camarão que sejam licenciados por órgãos ambientais.

Tal realidade já tinha sido discutida com uma nativa na qual esse ponto negativo é vislumbrado na seguinte afirmação: "Muitas empresas compram aqui, empresas grandes mesmo! Mas nenhuma faz nada além de comprar. Uma vez vieram com um carro de hospital para medir nossa pressão, tirar sangue e fazer outras coisas. Mas isso faz muito tempo" (Produtor 03). 
Embora a comunidade tenha o respaldo legal para a produção de camarão, observa-se no relato a inexistência de projetos sociais que possam melhorar as condições e saúde e qualidade de vida dos produtores locais. Nesse sentido, de acordo com Ostrenskyet al. (2007 p.148):

A única saída para conseguir escala de produção e conquistar o mercado está na organização. As indústrias querem contar sempre com uma escala de produção definida e com um padrão uniforme. Para atingir esse objetivo o apoio das associações de produtores é fundamental. O problema é que, na maioria dos casos, as associações funcionam principalmente como organizações reivindicadoras, quando deveriam trabalhar em sistema cooperativo, comprando insumos e vendendo a produção em conjunto.

A denominação alimento seguro depende não só de como o organismo aquático é cultivado, como também de toda a cadeia produtiva, incluindo-se o transporte,abate, processamento e armazenamento. Medidas que visem à manutenção da qualidade do alimento até chegar à mesa do consumidor final são indispensáveis. O cuidado com a produção e consumo de alimentos seguros reflete não só uma preocupação com a saúde pública, mas também influencia na economia (OSTRENSKI et al. 2007).

Nesse contexto, o padrão de qualidade visto na rede de restaurante é notório e de excelência internacional. Diante desse fato, procurou-se averiguarse o estabelecimento utiliza camarão que tenha sido produzido de forma sustentável, conforme relatos a seguir: "Sim. Procuramos sempre um padrão de qualidade. E nisso, nos asseguramos sobre a procedência de como nosso camarão é feito." (Gestor 03);“Pressupomos que sim, pois são licenciadas pelo IDEMA” (Gestor 02).

Todavia, a simples existência da certificação do licenciamento não é suficiente paradizer se tal produto vem de um modelo sustentável. Até porque conforme consta nos depoimentos, muitos dos criadouros têm a licença, mas nãoseguem as regras.

Nesse contexto, também foi averiguado a respeito da produção sustentável, onde se questionou como é estimulada e/ou organizada a ideia de sustentabilidade na percepção dos gestores da rede de Restaurantes Camarões, de acordo com os entrevistados:

Sustentabilidade está diretamente ligada ao meio ambiente. É um termo usado recentemente para tratar de conservação e definir ações e atitudes humanas que não comprometam o futuro das próximas gerações (Gestor, 1); "É a capacidade que o individuo ou um grupo de pessoas ou empresa tem de se manter dentro do ambiente sem causar impactos ao mesmo" (Gestor, 2); "É a forma de se realizar uma atividade econômica respeitando 
as leis e boas práticas (ambientais, trabalhistas, etc.) de forma a garantir a existência a longo prazo do negócio, bem como sua coexistência com a comunidade a que está envolvida(Gestor 3).

A partir disso, verifica-se que os discursos demonstram com clareza que o termo sustentabilidade é compreensível a todos os gestores da rede de restaurantes Camarões, mas que ainda não há um aprofundamento maior nessa área e/ou ações que de fato abranjam sustentabilidade em relação à origem e aos modos de produção.

Inserido nesse mesmo contexto, buscou-se também averiguar a percepção dos estudantes do curso de Aquicultura da UFRN, no sentido de compreender se esta atividade é sustentável e benéfica à comunidade. Tendo em vista que esses estudantes possuem conhecimento de campo, além de realizarem estudos periódicos na comunidade. Dessa maneira, foi relatado pelo Entrevistado-Estudante 01 que:

Saber afirmar se esses criadouros são, de fato, sustentáveis é complicado. Não existe uma regra! O produtor tem que se adequar ao meio e o meio se adequar ao produtor. Existem técnicas muito bem elaboradas na carcinicultura que são aplicadas aqui. Vendo por esse lado, a prática pode ser julgada correta. Sustentável, não. Pois é natural da prática se usar de artifícios para que o camarão chegue a um tamanho e peso ideal para 0 consumo e comercialização. Logo,se são utilizados técnicas que agridem de alguma forma o meio ambiente ela não pode ser considerada sustentável. Em geral e de grosso modo, posso afirmar que ela não agride tanto quanto as demais espalhadas pelo estado. Tem criadouros que jogam suas águas sujas em mangues, chegando até a prejudicar o ecossistema e biodiversidade natural do local. Sendo assim, Tibau do Sul tem um dos métodos mais próximos da sustentabilidade.

Faz-se necessário tomar conhecimento de alguns projetos que a comunidade acadêmica presta a localidade de Tibau do Sul, mais especificamente aos pequenos produtores de camarão. Foi relatado pelo Entrevistado-Estudante 01 que uma das medidas tomadas por essa parcela de acadêmicos é:

Hoje temos um projeto ainda em construção, mas, que já foi levado a comunidade de Tibau do Sul algumas vezes. Nos do curso de aquicultura tentamos fazer uma espécie de consultoria com os pequenos produtores, tentando assim facilitar a produção com técnicas ainda em experimento e também, diminuir alguns possíveis prejuízos causados pela prática da carcinicultura. Tentamos não utilizar ração com grandes quantidades de sódio, tentamos não utilizar cal na construção do criadouro, tentamos utilizar a água o máximo possível e de forma limpa, a fim de ser sempre utilizada em outras áreas no processo de criação.. enfim, tentamos facilitar a vida dos pequenos produtores que muitas vezes tentam fazer algo que seus pais e avôs fazem a muito tempo, só que sem técnica. Levamos a técnica e aprimoramos a sua produção. 
Em verdade, é necessário ainda realizar mais pesquisas a respeito desse assunto, tendo em vista que há muitos aspectos que não foram completamente abordados nesse manuscrito.

\section{CONSIDERAÇÕES FINAIS}

Tendo como ética a sustentabilidade e o movimento SlowFood: A prática da Carcinicultura na cidade de Natal-RN pode gerar impactos na sustentabilidade socioambiental local. Em relação ao caráter sustentável da produção, o processo se perde durante as etapas do método utilizado pelas fazendas. Faz-se necessária a fiscalização por parte dos órgãos responsáveis pelo licenciamento e melhoria da logística do processo.

É notória a necessidade de um investimento na capacitação dos produtores sobre o processo de criação. É fixa a ideia de sustentabilidade na percepção e no senso comum dos produtores, mas de forma dissociada à prática de seus criadouros. Os produtores reproduzem um ciclo de conhecimento apreendido da prática de seus antepassados.

A carciniculturaabastece o mercado turístico-gastronômicoe movimenta a economia local formal e informalmente. Todavia, faz-se necessária política deincentivos por parte de órgãos públicos e empresas sem fins lucrativos que apoiem as comunidades de pequenos produtores ao estabelecer critérios de produção mais sustentáveis.

A gestão da gastronomia tem uma percepção de qualidade do produto restrita ao peso e tamanho ideal do camarãoaceito na gastronomia turística, sem considerar aspectos sociais e ambientais inerentes aos modos de produção e origem do produto.

Outro aspecto que demanda estudos trata-se de avaliar a saúde de consumidores para avaliar impacto do consumo de camarão produzido pela aquicultura. 


\section{REFERÊNCIAS}

ABRESI - Associação Brasileira de Gastronomia, Hospedagem e Turismo.

Disponível em: <http://www.abresi.com.br>Acesso em: 20 mai. 2015.

ABCC - Associação Brasileira de Criadores de Camarão. Disponível em $<$ http://abccam.com.br/site/ > Acesso em 20 mai.2015.

AQUACULTURE BRASIL. Cultivo de camarão marinho em água doce. Disponível<http://www.aquaculturebrasil.com/2016/05/12/cultivo-de-camaraomarinho-em-agua-doces. Acesso em 20 dez. 2016.

AZAMBUJA, M. A Gastronomia como produto turístico. In: CASTROGIOVANNI, A. C. (org.) Turismo urbano. Editora Contexto: SP, 2000.

BENNI, Mario C. Politicas e Estratégias do Desenvolvimento Regional: Planejamento Integrado e Sustentável do Turismo. SP, 1999.

CANESQUI A.M.; DIEZ-GARCIA, R.W. Antropologia e Nutrição: um diálogo possível. Rio de Janeiro: Editora Fiocruz; 2005.

COSTA, S. C.; SCOCUGLIA, J. B. C. Em Busca da Sustentabilidade na Cidade do Sol. Brasil: 2008.

FAGLIARI, Gabriela Scuta. Turismo e Alimentação: Análises introdutórias. Editora Roca: SP, 2005.

IDEMA (INSTITUTO DE DESENVOLVIMENTO ECONÔMICO E MEIO AMBIENTE). Dados referentes á Quantidade de fazendas de camarão irregulares e Regulares e suas respectivas Áreas de ocupação e informações referentes e ao Plano de recuperação de Área Preservação Permanente, 2007.

KRIPPENDORF, J. Sociologia do Turismo: Para nova compreensão do lazer e das viagens. Editora Aleph: SP, 2000.

LEITE, L. A. Gastronomia corumbaense, característica e aspectos históricos. IV Simpósio sobre Recursos Naturais e Sócio-econômicos do Pantanal. Corumbá/MS. 2004. 
NILSSON J.H.; SVÄRD, A.C., WIDARSSON Å.; WIRELL, T. Cittáslow' ecogastronomic heritage as a tool for destination development. Currentlssues in Tourism14(4):373-386, 2011.

OLIVEIRA, G. D.; MATOS, K. M. C. Desmatamento gerado pela atividade da carcinicultura no município de Nísia Floresta (RN). Associação Brasileira de Engenharia de Produção. Brasil: 2007.

PETRINI, C. Slowfood: princípios da nova gastronomia.Editora Senac, SP. 2009.

OSTRENSKY,A.; BORGHETTI, J. R.; SOTO, D. Estudo setorial para consolidação deUma aquicultura sustentável no brasil. GIA: Curitiba, 2007.

QUEIROZ, F. L. N.; Alimentação regional saudável em unidade produtoras de refeições do sudeste brasileiro. Universidade de Brasília, 2008.

ROCHA, I. P. Carcinirultura Brasileira: Processos Tecnológicos, Impactos SócioEconômicos, Sustentabilidade Ambiental, Entraves e oportunidades.Brasil, 2010.

ROZIN, P. The meaning of food in our lives: a cross-cultural perspective on eating and well-being. JournalofNutritionEducationandBehavior, v.37, n.2, S107-12, 2005.

SANTOS, M.; CARNEIRO, S. G.; SOUZA, F. T. Proposta de Implementação de um Sistema Parai Monitoramento e Controle na Carciniultura, Diálogos $\mathrm{E}$ Ciência - Revista Eletrônica da Faculdade de Tecnológia e Ciências de Feira de Santana. Ano III, n. 6, dez. 2005.

SCHLÜTER, Regina G. Gastronomia e Turismo. EditoraAleph: SP, 2003.

WEINER, S. O manual Slow Food.2. E. Itália: Slow Food Editore, 2005.

YURTSEVEN, H. R. Sustainable gastronomic Tourism in Gokceada, local and authentic perspectives. International Journal of Humanities na Social Science, v.1, n. 18, 2001. 